\title{
BACIA DO RIO PIAUÍ-SE: CARTOGRAFIA DAS UNIDADES DE MODELADO DE RELEVO COM AUXÍLIO DE GEOPROCESSAMENTO
}

\author{
Lucas Marcone dos Santos ${ }^{(\mathrm{a})}$, Alexandre Herculano de Souza Lima ${ }^{(\mathrm{b})}$, Luan Lacerda Ramos ${ }^{(\mathrm{c})}$, \\ Ronaldo Missura ${ }^{(d)}$
}

\begin{abstract}
(a)Aluno do Departamento de Geografia/Universidade Federal de Sergipe - Campus São Cristóvão lcsmarcone@ gmail.com.
(b) Professor do Depto de Geografia da Universidade Federal de Sergipe - Campus São Cristóvão, ronaldomissura@hotmail.com

(b) Aluno do Departamento de Geografia/Universidade Federal de Sergipe - Campus São Cristóvão lcsmarcone@gmail.com.

(c) Aluno do Departamento de Geografia/Universidade Federal de Sergipe - Campus São Cristóvão lcsmarcone@gmail.com.
\end{abstract}

\section{Eixo: GEOTECNOLOGIAS E MODELAGEM ESPACIAL EM GEOGRAFIA FÍSICA}

\begin{abstract}
Resumo
O mapa geomorfológico nos ajuda a compreender as relações espaciais de interesse do geógrafo como vulnerabilidade e a potencialidade dos recursos do relevo (Tricart, 1965). Com uso de geotecnologia o mapeamento geomorfológico da bacia do Rio Piaú, foi executado na escala de 1:100.000. Aplicando a classificação taxonômica de Ross $(1992,1996)$, o mapeamento foi construído nas grandeza do $3^{\circ} \mathrm{e}$ $4^{\mathrm{o}}$ táxon que corresponde às unidades morfológicas ou aos padrões de formas semelhantes contidos nas unidades morfoesculturais e os tipos de formas de relevo. A metodologia aplicada aos modelados de acordo com o tipo de relevo se baseou no Manual Técnico de Geomorfogia do Instituto Brasileiro de Geografia e Estatística (IBGE). A metodologia aplicada do IBGE delimita os modelados de acordo com a seguinte classificação de compartimentos de relevo: Plaino Aluvial e Terraços/Planicies; Maciços Residuais; Pedimentos; Patamares; Cimeiras e Pediplanos intermontanos.
\end{abstract}

Palavras chave: Mapa Geomofologico; Geotocnologia; Bacia Hidrografica.

\section{Introdução}

No campo da Geografia da Física que tem como uma das bases teórica a categoria paisagem, e dentro desta categoria utilizamos como recorte para a análise a bacia hidrográfica e como método para tal usamos da Teoria Geral de Sistemas para compreender a organização dos elementos dos "sistemas" e a relação entre eles (CHRISTOFOLETTI, 1979).

A componente Geomorfológica dentro de uma análise sistêmica trata-se de um elemento de grande importancia, neste sentido o mapa geomorfológico se constitui um poderoso instrumento na espacialização desta componente da paisagem, permitindo representar desde o início das formas do relevo e suas relações com a estrutura e processos, bem como, com a própria dinâmica dos processos. Para Tricart (1965) o mapa geomorfológico nos ajuda a compreender as relações espaciais de interesse do geógrafo como vulnerabilidade e a potencialidade dos recursos do relevo.

Com uso de geotecnologia o mapeamento geomorfológico se procedeu no recorte espacial da bacia do Rio Piauí, à escala de 1:100.000. Aplicando a classificação taxonômica de Relevo usou as propostas de Ross 
XVII Simpósio Brasileiro

de Geografia Fisica Aplicada

I Congresso Nacional

de Geografia Física
OS DESAFIOS DA GEOGRAFIA FÍSICA NA FRONTEIRA DO CONHECIMENTO

Instituto de Geociências - Unicamp

Campinas - SP

28 de Junho à 02 de Julho de 2017

(1992, 1996), o mapeamento foi construído nas grandeza do $3^{\circ}$ e $4^{\circ}$ táxon que corresponde às unidades morfológicas ou aos padrões de formas semelhantes contidos nas unidades morfoesculturais e os tipos de formas de relevo. A metodologia aplicada aos modelados de acordo com o tipo de relevo se baseou no Manual Técnico de Geomorfogia do Instituto Brasileiro de Geografia e Estatística (IBGE) de 2009.

Que essa documentação sirva como de subsídio para a gestão da bacia hidrográfica que integra um conjunto de mapeamentos a serem realizados para viabilização do mapa geomorfológico do estado de Sergipe.

\section{Metodologia}

Para a compreensão da paisagem na geografia é necessário levar em conta sua dinâmica, dentro deste conceitos podemos utilizar a Teoria geral de Sistema na qual Christofoletti vai dizer que:

"Praticamente, a totalidade dos sistemas que interessam ao geógrafo não atua de modo isolado, mas funciona dentro de um ambiente e faz parte de um universo maior. Esse conjunto maior, no qual se encontra inserido o sistema particular que se está estudando, pode ser denominado de universo, o qual compreende o conjunto de todos os fenômenos e eventos que, através de suas mudanças e dinamismo, apresentam repercussões no sistema focalizado, e também de todos os fenômenos e eventos que sofrem alterações e mudanças por causa do comportamento do referido sistema particular”. (CHRISTOFOLETTI, 1979, p. 3).

Nessa linha de pensamento norteou o estudo dos "sistemas" nos ajudou a entender as características dinâmicas e a evolução das paisagens geomorfológicas estudadas (SOTCHAVA, 1978). Para uma análise das paisagens noção de escala é inseparável, assim, a classificação taxonômica de Ross (1996) nos auxiliou no mapeamento da Bacia hidrográfica do Rio Piauí, este foi elaborado dentro da escala 1:100.000, na ordem de grandeza taxonômica de $3^{\circ}$ e $4^{\circ}$, ou seja, unidades geomorfológicas ou padrões de formas semelhantes contidos nas unidades morfoesculturais e formas de relevo (ROSS, 1996, Figura 01). As unidades morfológicas, correspondentes ao agrupamento de formas relativas aos modelados, que são distinguidas pelas diferenças da textura na rugosidade do relevo, bem como pelo formato dos topos, vertentes e vales de cada padrão. 

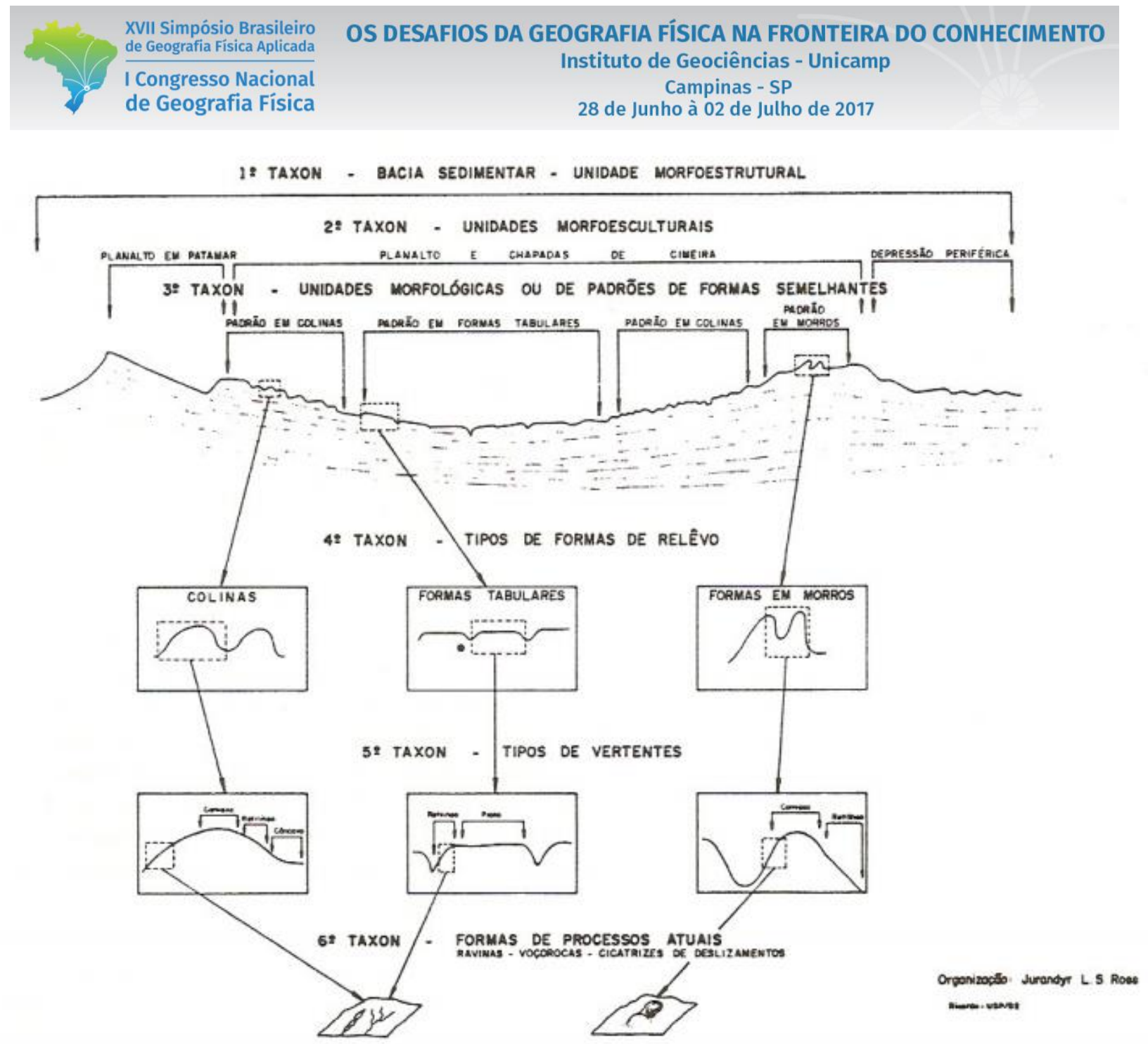

Figura 01. Representação esquemática das Unidades Taxonômicas . Fonte: Ross (1996)

Foi elaborado levantamento bibliográfico, e o objetivo foi viabilizar um mapeamento temático de semidetaIhe para a Bacia Hidrográfica do Rio Piauí no estado de Sergipe. A Bacia Hidrográfica do Rio Piauí possui uma área geográfica de 3.953,41 km², equivalentes a $19 \%$ do território estadual e abrange 15 municípios, com uma população de 432.000 habitantes aproximadamente. Localizada na parte sul do estado, é um dos mais importantes componentes da rede hidrográfica do estado de Sergipe (SRH 2014). O mapeamento em questão serve como documentação de subsídio para a gestão da bacia e integra um conjunto de mapeamentos a serem realizados para viabilização do mapa geomorfológico do estado de Sergipe.

Os materiais que foram utilizados neste projeto apresentam baixo custo de obtenção, grande parte deles pode ser obtido gratuitamente em órgãos governamentais. É o caso dos Modelos Digitais de Elevação (MDE) com dados altimétricos e de relevo sombreado, ambas obtidas no Banco de Dados 
Geomorfométricos do Brasil (TOPODATA) com resolução espacial de 30x30m (foram obtida as imagens de altimetria e relevo sombreado com as seguintes identificações: 10S39_; 10S375; 11S39_11S375) disponibilizadas gratuitamente pelo INPE (Instituto Nacional de Pesquisas Espaciais) e o recorte vetorial do tipo shape dos limites da Bacia Hidrográfica do Rio Piauí foi obtida no atlas digital da Secretaria de Recursos Hidricos (SRH) de 2014.

Foi usado o programa de Sistema de Informação Geográfica (SIG) QGIS versão 2.8 para processamento das imagens do relevo sombreado e imagens de radar obtidas no TOPODATA.

Dentro dos processamentos das imagens utilizando o QGIS aplicando a ferramenta Mosaico que fundiu as quatro imagens de SRTM para obter um único arquivo do tipo raster, os mosaicos passaram por um recorte conforme shape dos limites espaciais para ser adaptada a área da bacia hidrográfica que foi trabalhada. O mesmo se deu com a imagem de relevo sombreado (shaded relief) Fez-se um mosaico e depois recortado na área onde foi trabalhada.

A classificação dos modelados de acordo com o tipo de relevo se baseou no Manual Técnico de Geomorfogia do Instituto Brasileiro de Geografia e Estatística (IBGE). Construiu um arquivo do tipo shapefile, feitos de modo interpretativo visual o agrupamento de classes de modelados do relevo, delimitando-se do mais dissecado para o menos dissecado. Com a ajuda de arquivos vetoriais da área de estudo, os seguintes arquivos shapefiles: hidrografia, litologia, e geomorfologia (escala em nível estadual), todos obtidos através do atlas SRH 2014.

A metodologia aplicada para o mapeamento foi o de identificação das diferentes texturas do relevo, apresentadas nos modelos de relevo sombreado. A partir da identificação dos conjuntos texturais, foi criado um arquivo do tipo vetorial de polígonos e os conjuntos texturais delimitados a partir das ferramentas de edição do SIG. Tal metodologia vai de encontro segue os preceitos que o manual de Técnico de Geomorfologia do IBGE usa para delimitar os modelados de acordo com a seguinte classificação de compartimentos de relevo: Plaino Aluvial e Terraços/Planicies; Maciços Residuais; Pedimentos; Patamares; Cimeiras; Pediplanos intermontanos.

\section{Resultados e discusões}

Levando em conta o Mapeamento Geomofologico da Bacia do Rio Piauí-SE (Figura 2) foram encontrado 13 (treze) tipos de modelados na area da bacia. Os modelados encontrados foram: cimeira residual, cimeira estrutural, cristas, maciços residuais, pedimento conservado, pedimento dissecado, pediplano, pediplano intermontado, planície fluvial, tabuleiro conservado,tabuleiro dissecado, terraço fluvial e terraço marinho. Ainda, os modelados foram descritos quanto aos processos de dissecação e a forma de relevo 


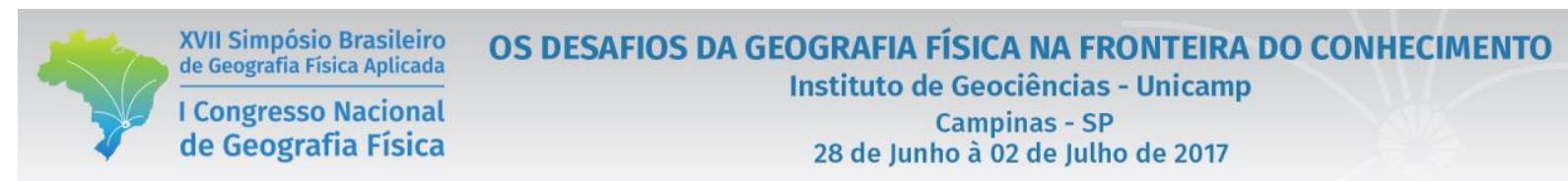

predominante, podendo ser dissecado ou conservado. Dissecado são as formas de relevos que foram entalhadas pelos agentes erosivos. Conservados apresenta maior resistência aos processos erosivos e menor entalhe da rede de drenagem e por conseguinte menor densidade de canais de drenagem (IBGE, 2009). 


\begin{tabular}{|c|c|}
\hline $\begin{array}{l}\text { XVII Simpósio Brasileiro } \\
\text { de Geografia Fisica Aplicada } \\
\end{array}$ & $\begin{array}{l}\text { OS DESAFIOS DA GEOGRAFIA FÍSICA NA FRONTEIRA DO CONHECIMENTO } \\
\text { Instituto de Geociências - Unicamp }\end{array}$ \\
\hline $\begin{array}{l}\text { I Congresso Nacional } \\
\text { de Geografia Física }\end{array}$ & $\begin{array}{l}\text { Campinas - SP } \\
28 \text { de Junho à } 02 \text { de Julho de } 2017\end{array}$ \\
\hline
\end{tabular}

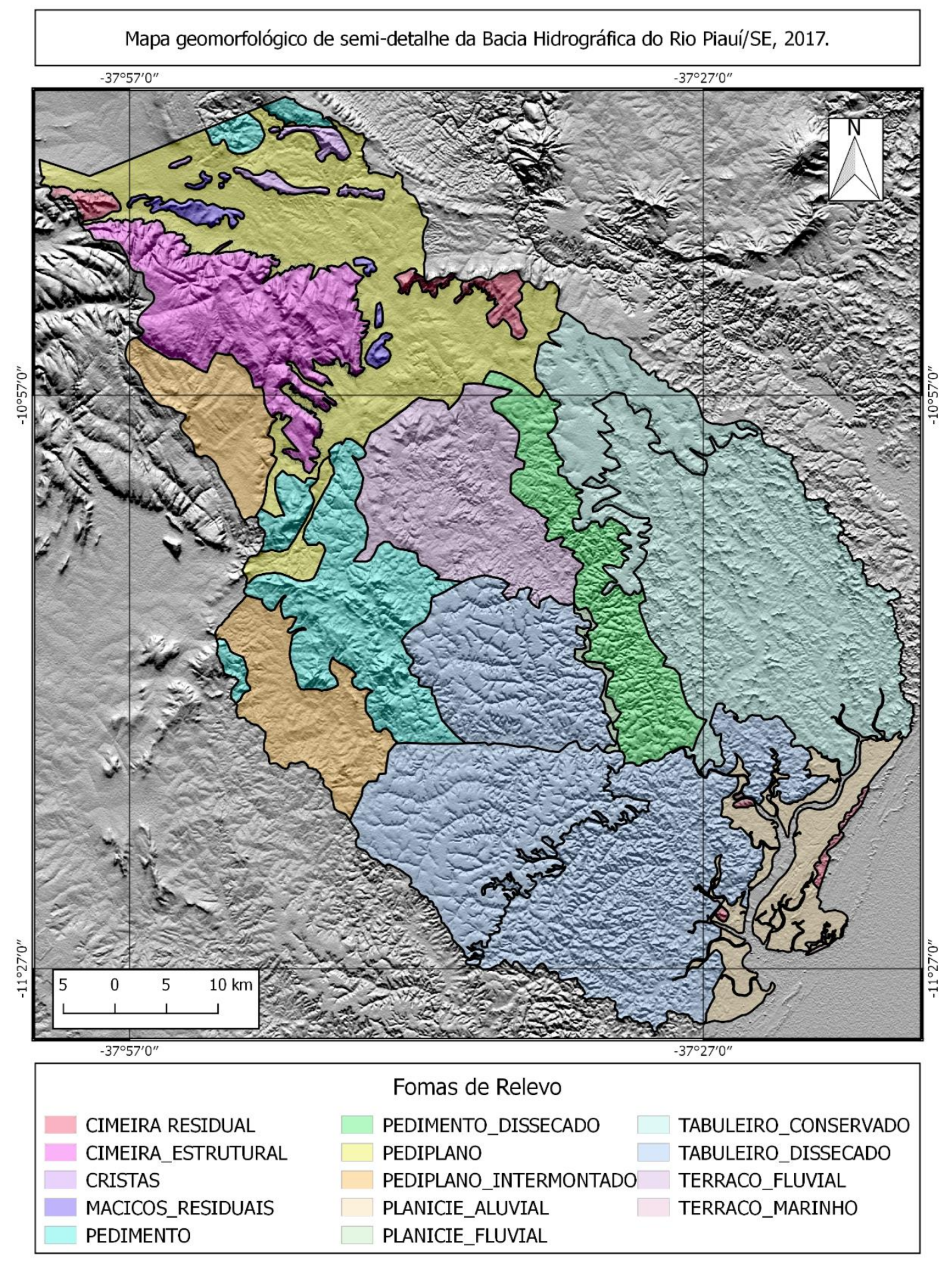

Elaborado por Lucas Marcone, em 2017.

Figura 2: Mapa geomorfológico de semi-detalhe da bacia hidrográfica do rio Piauí/SE. Elaborado por Lucas Marcone, em 2017. 
XVII Simpósio Brasileiro de Geografia Física Aplicada

I Congresso Nacional de Geografia Física
OS DESAFIOS DA GEOGRAFIA FÍSICA NA FRONTEIRA DO CONHECIMENTO

Instituto de Geociências - Unicamp

Campinas - SP

28 de Junho à 02 de Julho de 2017

De acordo com a metodologia adaptada do manual Técnico de Geomorfologia do IBGE encontramos esses tipos de feições (Tabela 1):

Tabela 1: Formas de relevo, área e representação dos modelados em relação ao total da bacia.

\begin{tabular}{|c|c|c|}
\hline FORMAS DE RELEVO & AREA $\left(\mathbf{K m}^{\mathbf{2}}\right)$ & $\begin{array}{c}\text { REPRESENTAÇÃo } \\
\text { (em \%) }\end{array}$ \\
\hline CIMEIRA RESIDUAL & 47,39 & 1,22 \\
\hline CIMEIRA ESTRUTURAL & 267,91 & 6,88 \\
\hline CRISTAS & 22,69 & 0,58 \\
\hline MACIÇOS RESIDUAIS & 24,85 & 0,64 \\
\hline PEDIMENTO & 299,16 & 7,68 \\
\hline PEDIMENTO DISSECADO & 199,21 & 5,11 \\
\hline PEDIPLANO & 539,73 & 13,86 \\
\hline PEDIPLANO INTERMONTADO & 269,45 & 6,92 \\
\hline PLANICIE FLUVIAL & 169,48 & 4,35 \\
\hline TABULEIRO CONSERVADO & 774,77 & 19,89 \\
\hline TABULEIRO DISSECADO & 1009,59 & 25,92 \\
\hline TERRAÇO FLUVIAL & 270,23 & 6,94 \\
\hline TERRAÇO MARINHO & 1,02 & 0,03 \\
\hline TOTAIS & $\mathbf{3 8 9 5 , 4 8}$ & $\mathbf{1 0 0}$ \\
\hline
\end{tabular}

- Cimeiras residuais e cimeiras estruturais - Cimeiras que correspondem aos níveis de maior altitude destacando-se das áreas do entorno, este fato deve se normalmente a maior resistência do embasamento rochoso ou de coberturas superficiais que proporcionam menor suscetibilidade aos processos erosivos. Apresenta-se com uma feição de topo moderadamente plano e desprovido de cobertura sedimentar e vegetação, encontrando-se dissecados pelos cursos d'água.

- Cristas - Forma de relevo residual alongada, isolada, com vertentes de declividade forte e equivalentes que se interceptam formando uma linha contínua. Ocorre em rochas metamórficas e intrusivas ou em outras litologias mais resistentes do que as circunvizinhas.

- Maciços Residuais (Serras. Serrotes e Inselbergs) - São corpos intrusivos ou blocos com maior resistência litológica, muitas vezes isolados, delimitados por encostas íngremes sob a influência sobretudo do intemperismo físico. Em virtude do gradiente de suas encostas estão sujeitos a processos denudacionais com presença, por vezes, de depósitos de tálus em sua base que tratam de formas residuais encontradas em terrenos de aplanamentos.

- Pedimentos dissecados e conservados - Pedimentos tratam dos compartimentos de relevo levemente inclinados estruturados em rochas do embasamento recobertos por coberturas detríticas e/ou material eluvial insipiente ocorrendo por extensas áreas em depressões e em bordas de áreas planálticas dando origem aos pediplanos quando há a coalescência de dois ou mais pedimentos. 
- Pediplano - Superfície de aplanamento parcialmente conservada, tendo perdido a continuidade em consequência de mudança do sistema morfogenético. Geralmente, apresenta-se conservada ou pouco dissecada.

- Pediplano Intermontado - Superfície rebaixada em relação ao entorno por processos erosivos em áreas planálticas, apresenta a mesma configuração de relevo que os pedimentos, porém circunscrito a uma área menor no interior de áreas planálticas.

- Planície fluvial - Área plana resultante de acumulação fluvial sujeita a inundações periódicas, correspondendo às várzeas atuais. Ocorre nos vales com preenchimento aluvial.

- Tabuleiro conservado e tabuleiro dissecado - Relevo cuja topografia é condicionada pela estrutura dos pacotes sedimentares. Neste caso, processos morfodinâmicos geram formas de relevo em conformidade com a estrutura geológica. As camadas mais resistentes sobressaem no relevo.

- Terraço fluvial - Acumulação fluvial de forma plana, levemente inclinada, apresentando ruptura de declive em relação ao leito do rio e às várzeas recentes situadas em nível inferior, entalhada devido às mudanças de condições de escoamento e consequente retomada de erosão. Ocorre nos vales contendo aluviões finas a grosseiras, pleistocênicas e holocênicas.

- Terraço marinho - Acumulação marinha de forma plana, levemente inclinada para o mar, apresentando ruptura de declive em relação à planície marinha recente, entalhada em consequência de variação do nível marinho, por processos erosivos ou, ainda, por neotectônica. Ocorre nas baixadas litorâneas pleistocênicas e holocênicas.

\section{Consideracões Finais}

A metodologia proposta para a elaboração do mapeamento gemofologico, pautada na análise do relevo e feições com características semelhantes resultou num importante mapa de diagnóstico que serve como de subsídio para a gestão da bacia hidrográfica que integra um conjunto de mapeamentos a serem realizados para viabilização do mapa geomorfológico do estado de Sergipe. Além de se constituir em um importante instrumento de subsídio ao ordenamento territorial rural sustentável. Este tipo de mapeamento torna-se ferramenta de grande valia ao planejamento do espaço geográfico, pois singulariza diversos modelados de relevo para áreas do 


\section{OS DESAFIOS DA GEOGRAFIA FÍSICA NA FRONTEIRA DO CONHECIMENTO \\ Instituto de Geociências - Unicamp \\ Campinas - SP \\ 28 de Junho à 02 de Julho de 2017}

território do Estado de Sergipe, que apresentava mapeamentos anteriores em escala de 1:250.000

que não apresentavam um grau de detalhamento tão especifico como o que apresentamos nesse trabalho.

\section{Bibliografia}

CHRISTOFOLETTI, A. Análise de Sistemas em Geografia. São Paulo: Hucitec-Edusp, 1979.

Ciências da Terra. n.13. São Paulo, 1971.

IBGE, Fundação Instituto Brasileiro de Geografia e Estatística. Manual Técnico de Geomorfologia. Coord. Bernardo de Almeida Nunes et al). Série Manuais Técnicos em Geociências. Número 5, R. de Janeiro, 2009.

ROSS, J. Geomorfologia ambiente e planejamento. S. Paulo:Contexto, 1990.

ROSS, J. S.Registro cartográfico dos fatos geomorfológicos e a questão da taxonomia do relevo. Rev. geografia. São Paulo, IG-USP, 1992

ROSS, Jurandyr Luciano Sanches. “Análise e Síntese na Abordagem Geográfica da Pesquisa para o

Planejamento Ambiental”. In: Revista do Departamento de Geografia n9, FFLCH-USP, São Paulo, 1995.

SOTCHAVA, V. B. Por uma teoria de classificação dos geossistemas de vida terrestre. Biogeografia. São Paulo: IGEO/USP 1978.

TRICART, J. Principes et méthodes de I geomorphologie. Paris:Masson Ed., 1965. 